\title{
Effect of intragastric acid stability of fat emulsions on gastric emptying, plasma lipid profile and postprandial satiety
}

\author{
Luca Marciani $^{1}$, Richard Faulks ${ }^{2}$, Martin S. J. Wickham ${ }^{2}$, Debbie Bush ${ }^{3}$, Barbara Pick ${ }^{3}$, Jeff Wright ${ }^{3}$, \\ Eleanor F. Cox ${ }^{4}$, Annette Fillery-Travis ${ }^{2,5}$, Penny A. Gowland ${ }^{4}$ and Robin C. Spiller ${ }^{1}$ * \\ ${ }^{1}$ Wolfson Digestive Diseases Centre, Queen's Medical Centre, Nottingham University Hospitals, University of Nottingham, \\ Nottingham NG7 2UH, UK \\ ${ }^{2}$ Model Gut Platform, Institute of Food Research, Colney, Norwich NR4 7UA, UK \\ ${ }^{3}$ Division of GI Surgery, Queen's Medical Centre, Nottingham University Hospitals, University of Nottingham, Nottingham NG7 \\ $2 U H, U K$ \\ ${ }^{4}$ Sir Peter Mansfield Magnetic Resonance Centre, School of Physics and Astronomy, University of Nottingham, Nottingham NG7 \\ $2 R D, U K$ \\ ${ }^{5}$ Centre for Research and Dissemination, PDF.net, 39 Harvey Lane, Norwich NR7 OBZ, UK \\ (Received 8 January 2008 - Revised 12 June 2008 - Accepted 16 June 2008 - First published online 5 August 2008)
}

Fat is often included in common foods as an emulsion of dispersed oil droplets to enhance the organoleptic quality and stability. The intragastric acid stability of emulsified fat may impact on gastric emptying, satiety and plasma lipid absorption. The aim of the present study was to investigate whether, compared with an acid-unstable emulsion, an acid-stable fat emulsion would empty from the stomach more slowly, cause more rapid plasma lipid absorption and cause greater satiety. Eleven healthy male volunteers received on two separate occasions $500 \mathrm{ml}$ of $15 \%$ (w/w) $\left[{ }^{13}\right.$ C]palmitate-enriched olive oil-in-water emulsion meals which were either stable or unstable in the acid gastric environment. MRI was used to measure gastric emptying and the intragastric oil fraction of the meals. Blood sampling was used to measure plasma lipids and visual analogue scales were used to assess satiety. The acid-unstable fat emulsion broke and rapidly layered in the stomach. Gastric emptying of meal volume was slower for the acid-stable fat emulsion $(P<0.0001$; two-way ANOVA). The rate of energy delivery of fat from the stomach to the duodenum was not different up to $t=110 \mathrm{~min}$. The acid-stable emulsion induced increased fullness $(P<0.05)$, decreased hunger $(P<0.0002)$, decreased appetite $(P<0.0001)$ and increased the concentration of palmitic acid tracer in the chylomicron fraction $(P<0.04)$. This shows that it is possible to delay gastric emptying and increase satiety by stabilising the intragastric distribution of fat emulsions against the gastric acid environment. This could have implications for the design of novel foods.

Magnetic resonance imaging: Echo-planar imaging: Stomach: Human studies

The current epidemic of obesity in the Western population ${ }^{(1)}$ can be related at least in part to the increasing consumption of pre-processed food that is high in added fat. The inclusion of fat impacts significantly upon both the palatability and the stability of common foodstuffs. The most common method of including fat is as an emulsion of finely dispersed oil droplets. This emulsion will enhance both the mouth-feel and stability of the food, for example, by changing the viscoelastic properties which gives rise to a perception of creaminess ${ }^{(2)}$. Furthermore the oil droplets can also be the principal carrier of aroma components and determine the rate of aroma release ${ }^{(3,4)}$ during the process of eating. Once eaten, the presence of the emulsion within the food will impact upon the gastrointestinal response ${ }^{(5-7)}$. Thus the presence of fat and the form of fat within a food impacts upon all aspects of a consumer's experience of that food from mouth-feel through to metabolism. Reducing the fat content of food whilst maintaining consumer satisfaction is not straightforward and it requires a good understanding of the relationship between food structure and its behaviour before and during digestion.

The physical state and the spatial distribution of fat within the gastric lumen during digestion are critical factors influencing the rate of fat delivery to the small intestine ${ }^{(8)}$. It is expected that in turn this will affect the rate of fat absorption and metabolism and the signalling between the gut and brain $^{(9-11)}$. Fat digestion commences in the mouth with the secretion of acid lipase from salivary glands, particularly important in infants ${ }^{(12)}$ and those with pancreatic insufficiency ${ }^{(13)}$. Previous invasive studies have shown that acid lipase from the salivary gland ${ }^{(14)}$ and from the gastric fundus $^{(15,16)}$ act within the stomach causing approximately

Abbreviations: AUC, area under the curve; EPI, echo-planar imaging; $t_{50 \%}$, time to empty half of the meal volume from the stomach.

* Corresponding author: Professor Robin C. Spiller, fax +44 115 9422232, email Robin.Spiller@nottingham.ac.uk 
$10 \%$ of dietary TAG to be hydrolysed to NEFA ${ }^{(17)}$. Together with gastric phospholipid and dietary emulsifiers, these NEFA facilitate the formation of emulsions with particle size $1-10 \mu \mathrm{m}^{(18)}$ suitable for the action of pancreatic lipases ${ }^{(19)}$. Inhibition of gastric lipase by Orlistat is associated with impaired intragastric hydrolysis and more rapid gastric emptying indicating that intragastric lipolysis is an important determinant of gastric emptying ${ }^{(16,20,21)}$.

Previous non-invasive imaging studies have investigated the gastric emptying of solid ${ }^{(22-26)}$ or liquid ${ }^{(22,27)}$ components of a meal from the stomach. Furthermore, a radio-pharmaceutical label for the fat component ${ }^{(28-30)}$ showed that the intracellular fat component of a test meal empties with the solid phase of a meal $^{(31)}$ whilst a liquid fat component that is free from the solid phase of the meal empties much more slowly than the aqueous phase of the meal ${ }^{(28,29)}$. However, gamma scintigraphy has limited spatial resolution and requires the use of radioactive labels, restricting its use in serial studies particularly in healthy volunteers.

More recently, MRI and in particular its ultra-fast variant echo-planar imaging (EPI) ${ }^{(32)}$ have been used successfully to investigate gastric emptying and motility ${ }^{(33-37)}$ and the effects of intragastric fat on antral flow and emptying ${ }^{(8,38)}$. MRI represents a unique tool to carry out such investigations as its high spatial resolution allows detailed description of the spatial distribution and emptying of multiphase intraluminal contents ${ }^{(8,38,39)}$ by virtue of its unique sensitivity to changes in the proton environment. Furthermore, we have recently validated a method to assess the fat fraction in an oil-inwater emulsion both in vitro and in vivo within the gastric lumen using inversion recovery EPI to measure the NMR longitudinal relaxation time and an empirical model of two non-exchanging compartments ${ }^{(40)}$.

Our previous studies have shown that acid-stable emulsions stimulate greater cholecystokinin release and are associated with delayed gastric emptying ${ }^{(41)}$, compared with acid-unstable emulsions. The mechanism for these differences is uncertain. Stable emulsions, which do not break under acid conditions, present a larger surface area for lipolysis, which may cause greater concentrations of NEFA reaching the duodenum, where they can exert their satiating effect both by acting on fat-sensitive enteroendocrine cells, and by delivering lipid-laden chylomicrons into the venous and lymphatic systems. In contrast, acid-unstable emulsions in which the fat layer empties after the aqueous phase, deliver fat with a markedly reduced interface area. Since the lipolysis takes place almost exclusively at the fat-aqueous interface, lipolysis products are likely to be created more slowly in the duodenum and upper small bowel.

We therefore hypothesised that acid-stable meals would not only empty more slowly but that once lipid entered the duodenum it would be more rapidly hydrolysed, and by increasing the local concentration of NEFA would stimulate more cholecystokinin release, and that this would be associated with more prolonged satiety. Our aims were therefore: (1) to confirm the differential gastric-emptying rates between acidstable and -unstable fat emulsions observed previously; (2) to investigate if the acid-stable emulsion increased satiety significantly; (3) to determine if this was related to plasma lipid levels.

\section{Materials and methods}

\section{Acid-stable and acid-unstable oil emulsion test meals}

The two oil-in-water emulsion test meals used in the present study were developed and characterised previously on the bench and in vivo ${ }^{(40-42)}$. They have equal lipid content (50 g fat), equal energy content $(3150 \mathrm{~kJ})$ and equal mean oil droplet size distribution $(3.6 \mu \mathrm{m})$. However, one oil-in-water emulsion test meal (the 'acid-stable' emulsion meal) is designed to remain intact and the other (the 'acid-unstable' emulsion meal) to break in two distinct phases in the acid gastric environment. The difference in gastric acid stability is achieved by using two similar emulsifiers that differ only in one polyoxyethylene group and a double bond on the NEFA chain. Polyoxyethylene sorbitan monostearate Tween 60 (E491; Macphie, Glenbervie, Kincardineshire, UK) was used as surfactant for the acid-stable emulsion and sorbitan monooleate Span 80 (E494; Esterchem Ltd, Leek, Staffs, UK) for the acid-unstable emulsion. The oil-in-water emulsions were prepared at room temperature by mixing $15 \%(\mathrm{w} / \mathrm{w}) \quad\left[{ }^{13} \mathrm{C}\right]$ palmitate-enriched olive oil (see below for ${ }^{13} \mathrm{C}$-labelling methods) and $2.5 \%(\mathrm{w} / \mathrm{w})$ surfactant with deionised, sterile water containing trace amounts of sweetener and coffee flavouring, in a PB20E Waring blender (Waring, Torrington, CT, USA) for $90 \mathrm{~s}$.

Batches of the $\left[{ }^{13} \mathrm{C}\right]$ palmitate-enriched oil were prepared beforehand as follows: $640 \mathrm{~g}$ olive oil was weighed into a 1 litre glass beaker. The oil beaker was put on a stirrer hotplate and warmed (to less than $60^{\circ} \mathrm{C}$ ) whilst being stirred using a large magnetic stirrer bar. Then $6.4 \mathrm{~g}\left[1,2,3,4-{ }^{13} \mathrm{C}_{4}\right]$ hexadecanoic acid (99\% AP; CK Gas Products Ltd, Hook, Hants, UK) were slowly added. This NEFA is a naturally occurring component in most vegetable oils and is safe for human consumption. The solid $\left[1,2,3,4-{ }^{13} \mathrm{C}_{4}\right]$ hexadecanoic acid dissolved in the oil which was thoroughly mixed by continuing stirring for $30 \mathrm{~min}$. Portions $(80 \mathrm{~g})$ of the $\left[{ }^{13} \mathrm{C}\right]$ palmitate-enriched oil were then dispensed into $150 \mathrm{ml}$ screw-top plastic bottles, one bottle for each experiment. The headspace of the bottles was flushed thoroughly with Ar and the bottles sealed tightly and stored at room temperature (since the $\left[1,2,3,4-{ }^{13} \mathrm{C}_{4}\right]$ hexadecanoic acid would crystallise out in a fridge) and in the dark for use during the study. On each occasion $75 \mathrm{~g}$ of the palmitate-enriched oil were used to prepare the test meal and the remaining $5 \mathrm{~g}$ of palmitate-enriched oil were retained and frozen at $-70^{\circ} \mathrm{C}$ to determine later the baseline concentration of the label by GC/MS. The total ingested labelled $\left[1,2,3,4-{ }^{13} \mathrm{C}_{4}\right]$ hexadecanoic acid was $0.75 \mathrm{~g}$ per $500 \mathrm{ml}$ oil emulsion meal.

\section{Volunteers and study design}

Twelve healthy male volunteers were recruited. Their health and suitability for MRI scanning was assessed using medical and safety questionnaires. Upon enrolment, a screening blood sample was taken to test for hyperlipidaemia, anaemia and glucose levels. Eleven subjects, aged 24 (SE 1) years and with BMI 23.8 (SE 0.7$) \mathrm{kg} / \mathrm{m}^{2}$, completed the study and one withdrew. Subjects were asked to attend on two separate experimental morning sessions (approximately $7 \mathrm{~d}$ apart), having fasted overnight on each occasion. Before the experimental session, the subjects were also asked to avoid alcohol 
and concomitant medications for $24 \mathrm{~h}$, caffeine and strenuous exercise for $18 \mathrm{~h}$ and to have a light, non-fatty dinner on the evening before the experiments. This was checked on the study day using a daily eligibility questionnaire. On the study day the subject was cannulated in a forearm vein using an 18GA BD Venflon Pro cannula (Becton Dickinson Infusion Therapy, Helsingborg, Sweden). Each volunteer then drank, within $10 \mathrm{~min}, 500 \mathrm{ml}$ of one of the two emulsion meals (containing $50 \mathrm{~g}$ fat each), given in random order. The time when meal ingestion started was defined as $t=0 \mathrm{~min}$. At $t=4.5 \mathrm{~h}$ the subjects ate a standard, low-fat cheese and salad sandwich meal with still water. This meal was chosen as it was low in fat and highly acceptable. One of the twelve volunteers withdrew during the first experiment due to poor acceptance of the cannulation procedure and his data were excluded from the study.

The volunteers' sense of fullness, appetite and hunger was monitored at baseline and at hourly intervals for $12 \mathrm{~h}$ using visual analogue scales ${ }^{(43,44)}$.

\section{Blood collection and analysis}

Venous blood samples $(12 \mathrm{ml})$ were collected at baseline and at $30 \mathrm{~min}$ intervals after feeding for the first $2 \mathrm{~h}$ and then at $1 \mathrm{~h}$ intervals up to $12 \mathrm{~h}$. The blood was transferred into chilled lithium-heparin tubes, mixed by inversion and cooled in an ice-bath. Plasma $(5 \mathrm{ml})$ was separated by centrifugation at $5000 \mathrm{~g}$ for $10 \mathrm{~min}$ at $4^{\circ} \mathrm{C}$, and then transferred to tubes and stored at $-80^{\circ} \mathrm{C}$ for analysis.

Plasma TAG were measured on a COBAS ${ }^{\circledR}$ (Roche Diagnostics Ltd, Burgess Hill, West Sussex, UK) blood analyser using a standard TAG kit. Plasma chylomicrons were separated $^{(45)}$ by ultra-centrifugation of $3.8 \mathrm{ml}$ plasma. The chylomicrons appeared as a milky smear on the top of the tube. The centrifuge tubes were carefully drained to avoid disturbing the chylomicrons, cut up with a scalpel and the chylomicron fraction carefully washed into a volumetric flask $(5 \mathrm{ml})$, made to volume and mixed well by sonication. The chylomicron fractions were transferred to glass tubes and frozen at $-80^{\circ} \mathrm{C}$.

To extract the lipids, $2 \mathrm{ml}$ chylomicron emulsion were transferred to a $50 \mathrm{ml}$ glass centrifuge tube and $10 \mathrm{ml}$ methanol were added and mixed well. Chloroform $(10 \mathrm{ml})$ was added and mixed well. The tubes were left to rest for $5 \mathrm{~min}$ and then $10 \mathrm{ml}$ of water were added. The samples were centrifuged at $1000 \mathrm{~g}$ to separate the phases. A portion $(8 \mathrm{ml})$ of the lower chloroform phase was aspirated and transferred into glass tubes and the solvent dried off at $35^{\circ} \mathrm{C}$ under a stream of $\mathrm{N}_{2}$. If residual traces of water were present they were removed by co-distillation with acetone. An internal standard ( $1 \mathrm{ml}$ triheptadecanoin $(200 \mu \mathrm{g} / \mathrm{ml}$; Sigma $)$ in chloroform containing butylated hydroxytoluene $(0 \cdot 1 \mathrm{~g} / \mathrm{l}))$ was added and dried under a stream of $\mathrm{N}_{2}$ at $35^{\circ} \mathrm{C}$. The dry TAG could then be stored at $-80^{\circ} \mathrm{C}$ in solid $\mathrm{CO}_{2}$ in sealed tubes for several weeks.

For the hydrolysis and methylation of TAG, $5 \mathrm{ml}$ of $\mathrm{HCl}-n$ hexane-propan-2-ol (1:10:40, by vol.) were added to each tube and vortex mixed for $5 \mathrm{~min}$. The tubes were left for 30 min to allow the reagent to hydrolyse the TAG to NEFA. Water $(2 \mathrm{ml})$ was then added to each tube and mixed. Next $n$-hexane $(2 \mathrm{ml})$ was added and mixed well. The samples were then centrifuged if needed to separate the phases and approximately $2 \mathrm{ml}$ of the $n$-hexane upper layer were transferred to a tube. The $n$-hexane phase was dried under a stream of $\mathrm{N}_{2}$ at $35^{\circ} \mathrm{C}$. If residual traces of water were present they were removed by co-distillation with acetone. The dried residue was dissolved in $50 \mu \mathrm{l} n$-hexane and $1 \mathrm{ml} 14 \% \mathrm{BF}_{3}$ in methanol was added. The lower third of the capped-off tube was heated at $62^{\circ} \mathrm{C}$ in a water-bath for $10 \mathrm{~min}$ under vigorous stirring with a magnetic bar. The heating and stirring procedure was continued until all beads of lipid were dissolved. The samples were cooled and water $(1 \mathrm{ml})$ and then $n$-hexane $(2 \mathrm{ml})$ were added. The tubes were vortex mixed and centrifuged to separate the layers cleanly. The upper $n$-hexane layer was transferred to a dry tube and dried under a stream of $\mathrm{N}_{2}$ at $35^{\circ} \mathrm{C}$. The dried residue was re-dissolved in $n$-hexane $(200 \mu \mathrm{l})$, transferred to an auto-injector vial and sealed. The methyl esters in the sealed auto-injector vials were not kept for more than 1 week in a cool $\left(6^{\circ} \mathrm{C}\right)$ dark place.

For the GC/MS analysis the methyl esters of the fatty acids were separated by capillary GC and the peak ratios of $\mathrm{C} 16$ and $\mathrm{C} 17$ were used to quantify the total hexadecanoic acid present. The mass spectrometer was set to monitor masses of the $\left[{ }^{12} \mathrm{C}\right]$ hexadecanoic acid ester $(\mathrm{M}), \mathrm{M}+1, \mathrm{M}+4$ and $M+5$. It was assumed here that the labelled fatty acid would be incorporated into TAG in the molar ratio of its presence in the enterocyte and therefore would be the only suitable marker of total lipid absorbed. The ratio of labelled and natural abundance hexadecanoic acid was then calculated.

\section{Echo-planar magnetic resonance imaging measurements}

Single-shot echo-planar images (EPI) ${ }^{(46)}$ were acquired on a whole-body $0.5 \mathrm{~T}$ purpose-built MRI scanner equipped with actively shielded gradients and a $50 \mathrm{~cm}$ diameter bird-cage coil. An in-plane resolution of $3.5 \mathrm{~mm} \times 2.5 \mathrm{~mm}$ and slice thickness of $1 \mathrm{~cm}$ was used throughout the experiments. Each image was acquired in $130 \mathrm{~ms}$ using a $128 \times 128$ matrix with an effective echo time of $40 \mathrm{~ms}$. At each time point to measure the gastric volumes ${ }^{(36)}$ a transverse, multislice set of echo-planar images of the stomach contents was rapidly acquired in only a few seconds. After this, to measure the fat fraction of the meal in the stomach $^{(40)}$, the NMR longitudinal relaxation time was measured on a single slice, positioned on the stomach body, using single-shot inversion recovery EPI with a hyperbolic secant inversion pulse at eight inversion times varying from 23 to $2000 \mathrm{~ms}$ with a repetition time of $25 \mathrm{~s}$. On the same slice, to visualise fat emulsion creaming ${ }^{(42)}$, spin-echo echo-planar images were acquired using eight echo times from 60 to $960 \mathrm{~ms}$. The repetition time was $10 \mathrm{~s}$ with a total acquisition time of $2.7 \mathrm{~min}$. The volunteers' stomachs were imaged until they were apparently emptied. Volunteers were asked to hold their breath before each image acquisition to minimise diaphragmatic displacement. The volunteers were trained to lie supine and sit up on the scanner bed so that they kept their left side uppermost. Padding on the scanner bed was used to keep their left-hand side higher than the right during imaging. These procedures mimicked the intragastric behaviour in the upright posture by preventing fat that layered in the stomach from floating near the pylorus and entering the duodenum before the aqueous phase ${ }^{(38)}$. In between scanning, volunteers were asked to sit 
upright, lying down on the scanner bed only for the short time necessary to acquire the images.

\section{Satiety assessment}

Before meal ingestion, after meal ingestion and then every $1 \mathrm{~h}$ up to $12 \mathrm{~h}$ the volunteers were asked to indicate on visual analogue scales ${ }^{(43,44)}$ their sense of fullness $(1=$ 'I feel not full', $10=$ 'I feel extremely full'), hunger $(1=$ 'I do not feel hungry', $10=$ 'I feel extremely hungry') and appetite ( $1=$ 'I would eat nothing', $10=$ 'I would eat an enormous meal') ${ }^{(41)}$. The satiety assessment was carried out in identical, controlled conditions for all subjects and before blood samples were taken.

\section{Ethical considerations}

The same $500 \mathrm{ml}$ fat emulsion test meals were used in previous studies $^{(40-42)}$ and they are comparable in volume to a large conventional meal. The insertion of a cannula in a forearm vein and serial blood sampling are procedures that carry a small risk of transient discomfort and were performed by two nurses experienced in the procedure. MRI scanning is a non-invasive procedure which is safe provided that the subjects are screened for suitability (for example, no metal implants or pacemakers) and it is well tolerated. The present study was approved by the Nottingham University Hospitals Research Ethics Committee in accordance with the Declaration of Helsinki (2000) and the study was conducted according to good clinical practice principles. All volunteers gave informed written consent before the experiments.

\section{Data analysis}

Data in the results section and in the graphs are shown as mean values with their standard errors.

Gastric emptying. Measurements of the volume of the aqueous phase of the gastric contents were carried out by manually tracing a region of interest around the meal within the stomach on each slice using Analyse software (Biomedical Imaging Resource, Mayo Foundation, Rochester, MN, USA) and summing across the slices to determine the total volume. The averaged datasets of volume against time were then analysed by calculating the time for half emptying $\left(t_{50 \%}\right)$ and area under the curve (AUC). The intra-operator error on such measurements is typically of the order of $5 \%$.

Magnetic resonance imaging measurements of oil fraction. On the inversion recovery EPI datasets a region of interest was traced around the bulk of the meal in the stomach body using again the Analyse software. The edges of the stomach itself and any floating fat layers were avoided. The signal intensities of the region of interest for different inversion times were then fitted to a model described previously ${ }^{(40,42)}$, to determine the fat fraction of the bulk of the meal in the stomach body.

Satiety. The satiety scores were plotted against time for each experiment and AUC calculated and averaged for each meal.

Rates of energy delivery from the stomach. Having found the gastric volumes $V_{\mathrm{a}}$ and $V_{\mathrm{b}}$ at time points $t_{\mathrm{a}}$ and $t_{\mathrm{b}}$ and also the corresponding intragastric oil fractions $f_{\mathrm{a}}$ and $f_{\mathrm{b}}$, it was possible to estimate the volume of oil leaving the stomach between time $t_{\mathrm{a}}$ and time $t_{\mathrm{b}}$ as $\left(V_{\mathrm{a}}-V_{\mathrm{b}}\right)\left(f_{\mathrm{a}}+f_{\mathrm{b}}\right) / 2$ (making the approximation of linear emptying and change in fat fraction over the interval $t_{\mathrm{b}}-t_{\mathrm{a}}$ ). It was therefore possible to estimate the mean cumulative mass of oil leaving the stomach with time and hence the overall rates of energy delivery from the stomach to the lower gastrointestinal tract for both emulsion meals. Since reliable oil fraction data for the acidunstable meal were available only up to $t=110 \mathrm{~min}$, the rates of energy delivery for the two emulsion meals could only be compared from $t=0-110 \mathrm{~min}$.

Plasma lipid measurements. The plasma was assayed for total TAG. The rate of absorption of the olive oil in the test emulsion was calculated from the rate of appearance and disappearance of the of the $\left[1,2,3,4-{ }^{13} \mathrm{C}_{4}\right]$ hexadecanoic acid from the chylomicron fraction using the internal standard. It was assumed that the entire chylomicron fraction was recovered and the total plasma volume was estimated based on the weight, sex and age of the volunteers using a nomogram ${ }^{(47)}$.

\section{Statistical analysis}

The statistical analysis was carried out using GraphPad Prism version 4.01 (GraphPad Software Inc., San Diego, CA, USA). Data were first tested for normality of the distribution using Shapiro-Wilk's normality test. Having determined that the data were normally distributed, a twoway repeated-measures ANOVA was carried out to assess the effect of the fat emulsion meals on the outcome measures. After this, statistical analysis of related variables was performed using the two-tailed paired Student's $t$ test. The correlation $r$ was computed to assess the goodness of fit for the gastric-emptying curves.

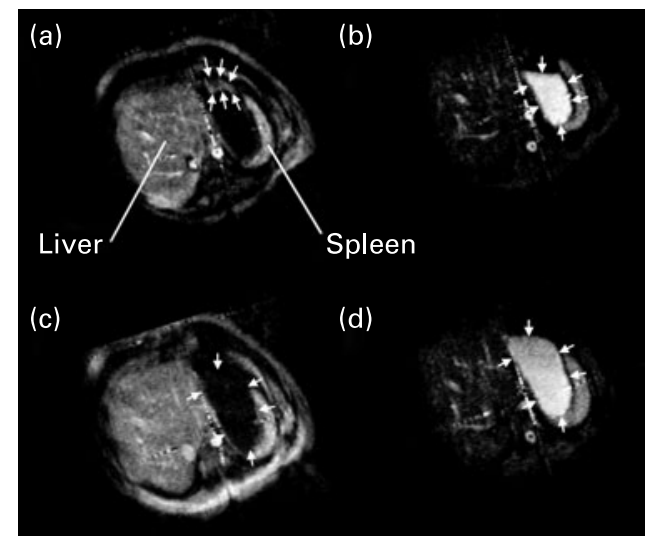

Fig. 1. Transverse inversion recovery echo-planar magnetic resonance images acquired across the body of the stomach of one volunteer at $t=40$ min after ingestion of the acid-unstable fat emulsion meal ( $a$ and $b$ ) and the acid-stable fat emulsion meal ( $c$ and d). The imaging inversion time in (a) is set to null the bulk water phase of the acid-unstable meal and a fat layer (indicated by the white arrows) can be clearly seen floating on top of the stomach for this meal. In the corresponding image for the acid-stable meal (c) no fat layer is observed and the stomach contents yield a low fat background signal (indicated by the white arrows) that appears to be homogeneous. In (b) the imaging inversion time is set to null the fat layer of the acid-unstable meal. The bulk water phase (indicated by the white arrows) can now be seen very bright. In the corresponding image for the acid-stable meal (d) the bulk water phase, indicated by the white arrows, appears less bright than in (b). For details of subjects and procedures, see the Materials and methods section. 


\section{Results}

The eleven subjects that completed the study tolerated the experimental procedures well and only one additional subject withdrew because of discomfort associated with the forearm vein cannulation. The images showed that the acid-stable emulsion meal did not phase separate in the stomach whilst the acid-unstable meal broke and layered rapidly in the stomach (Fig. 1). In the spin-echo echo-planar images (which are weighted towards the transverse relaxation time of the sample) the acid-stable emulsion showed a reduced signal in the upper part of the stomach contents, which is consistent with creaming of oil droplets without coalescence which was previously reported ${ }^{(42)}$.

\section{Gastric emptying}

The average gastric-emptying curves for the aqueous phase of the stomach contents are shown in Fig. 2. The effect of the two different fat emulsion meals on gastric emptying was significant $(P<0.0001$; two-way ANOVA). The acid-stable meal emptied from the stomach linearly (Pearson's $r$ 0.99), whilst the acid-unstable meal emptied exponentially (Pearson's $r$ 0.97). No lag phase was observed. Gastric emptying as assessed by the AUC was faster for the acid-unstable emulsion (33 922 (SE 3664) $\mathrm{ml} \times$ min) than for the acid-stable emulsion (88 422 (SE 3043) $\mathrm{ml} \times \mathrm{min})(P<0 \cdot 0001$; two-tailed paired Student's $t$ test). The mean $t_{50 \%}$ for the acid-unstable emulsion (67 (SE 11) min) was significantly faster than the $t_{50 \%}$ of the acid-stable emulsion (185 (SE 15) min) $(P<0 \cdot 0002$; two-tailed paired Student's $t$ test).

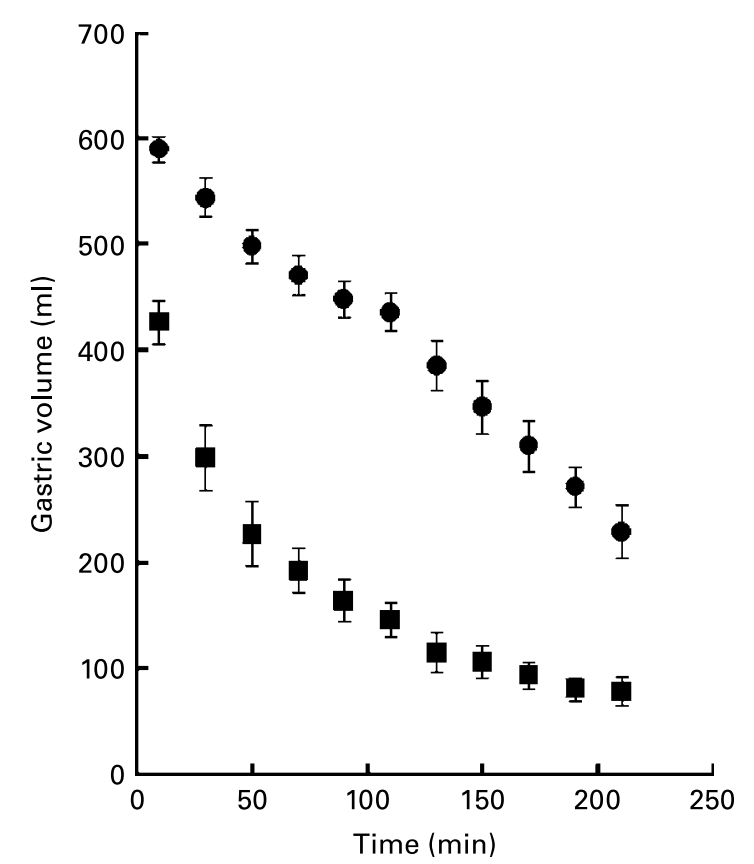

Fig. 2. Gastric emptying data (gastric meal volumes $v$. time) for the acidstable $(\bullet)$ and the acid-unstable $(\square)$ emulsion meals. Values are means, with standard errors represented by vertical bars. The gastric half-emptying time of the acid-unstable emulsion meal was faster than that of the acidstable emulsion $(P<0.0002$; two-tailed paired Student's $t$ test). For details of subjects and procedures, see the Materials and methods section.

\section{Oil fraction}

The plot of the mean oil fraction of the bulk of both meals in the stomach body (excluding any floating layer) is shown in Fig. 3. Due to the faster emptying of the acid-unstable emulsion meal it was difficult to place the single imaging slice on the intragastric contents reliably at later emptying times, hence the inversion recovery measurements for this meal are available only up to $t=110 \mathrm{~min}$. As expected, the oil fraction of the acid-unstable meal drops very rapidly after ingestion due to emulsion breaking whilst the oil fraction of the acidstable meal does not decline in the acid gastric environment (Fig. 3). The effect of the two different fat emulsion meals on the oil fraction was significant $(P<0.0001$; two-way ANOVA). The AUC for the oil fraction between $t=10 \mathrm{~min}$ and $t=110 \mathrm{~min}$ for the acid-stable meal was found to be 13 (SE 1) $\% \times$ min, which was significantly higher than the AUC for the acid-unstable meal (4 (SE 1) $\% \times$ min) $(P<0 \cdot 001$; two-tailed paired Student's $t$ test $)$.

\section{Satiety}

The average visual analogue scale scores for the volunteers' sense of fullness, hunger and appetite for both emulsion meals are plotted in Fig. 4 (a), (b) and (c) respectively. The effect of the two different fat emulsion meals on satiety was significant $(P<0.05$ for fullness, $P<0.0002$ for hunger and $P<0.0001$ for appetite; two-way ANOVA). The volunteers'

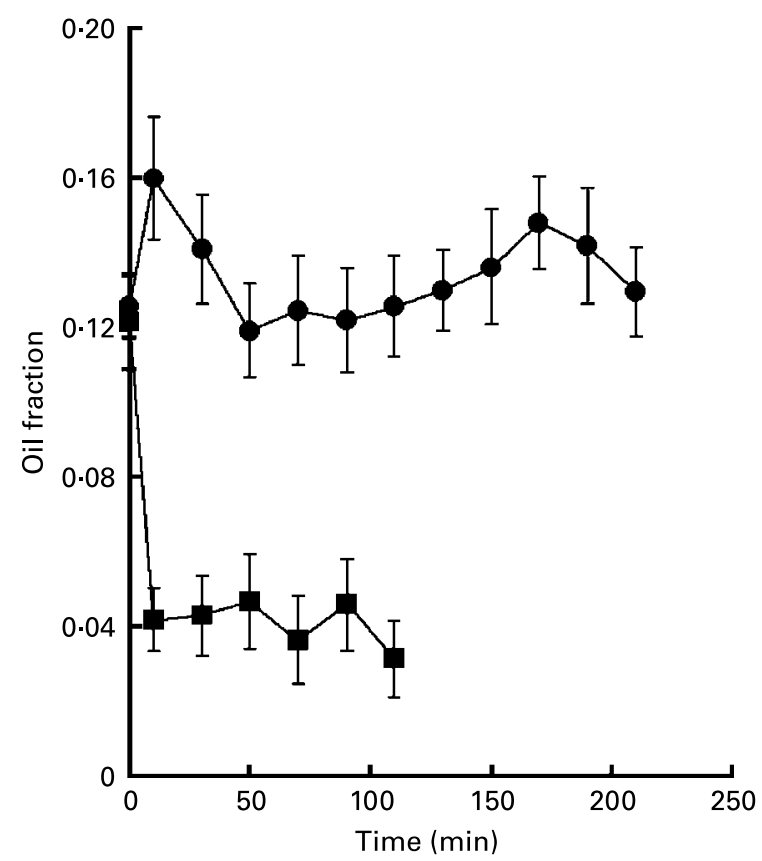

Fig. 3. Plots of the fraction of oil (whereby on the vertical scale 1 corresponds to $100 \%$ oil and 0 equals $0 \%$ oil) in the emulsions in the gastric lumen with time estimated using the in vivo echo-planar MRI measurements for the acid-stable $(\bullet)$ and the acid-unstable $(\boldsymbol{\square})$ emulsion meals. Due to the faster emptying of the acid-unstable emulsion meal the inversion recovery oil fraction measurements for this emulsion meal are available only up to $t=110 \mathrm{~min}$. Values are means, with standard errors represented by vertical bars. The area under the curve for the oil fraction between $t=10 \mathrm{~min}$ and $t=110 \mathrm{~min}$ was higher for the acid-stable meal than for the acid-unstable meal $(P<0.001$; two-tailed paired Student's $t$ test). For details of subjects and procedures, see the Materials and methods section. 

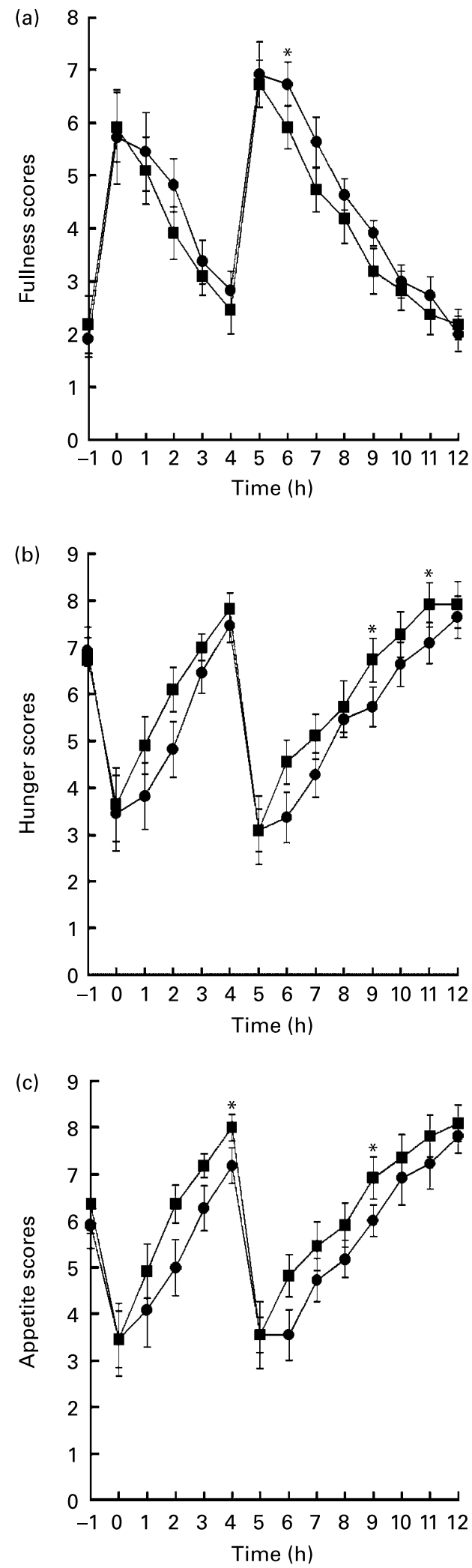

Fig. 4. Satiety scores for the acid-stable (๑) and acid-unstable (घ) emulsion meals. The graphs show the scores for the sense of (a) fullness, (b) hunger and (c) appetite. Values are means, with standard errors represented by vertical bars. ${ }^{*} P<0.05$. The effect of the two different fat emulsion meals on satiety was significant $(P<0.05$ for fullness, $P<0.0002$ for hunger and $P<0.0001$ for appetite; two-way ANOVA). For details of subjects and procedures, see the Materials and methods section. sense of hunger for the acid-stable meal was significantly decreased as shown by integrating the AUC from 0 to $12 \mathrm{~h}$. This was found to be 69 (SE 4) v. 77 (SE 5) score $\times$ h for the acid-unstable meal $(P<0.02$; two-tailed paired Student's $t$ test). The sense of appetite was also significantly decreased for the acid-stable meal (70 (SE 5) score $\times$ h) compared with that for the acid-unstable meal (79 (SE 4) score $\times$ h) $(P<0.03$; two-tailed paired Student's $t$ test). The AUC for the sense of fullness was not different between the acidstable emulsion (58 (SE 4) score $\times$ h) and the acid-unstable meal (53 (SE 4) score $\times \mathrm{h}) \quad(P<0 \cdot 5$; two-tailed paired Student's $t$ test). Looking at differences between individual time points, significant differences in satiety were found after the second meal at $t=6 \mathrm{~h}$ for the sense of fullness and later at $t=9 \mathrm{~h}$ and $t=11 \mathrm{~h}$ for the sense of hunger and at $t=9 \mathrm{~h}$ for the sense of appetite $(P<0 \cdot 05)$.

\section{Rates of energy delivery from the stomach}

The oil fraction measurements were carried out in the bulk of the meal, excluding any layer arising from breaking of the acid-unstable emulsion in the gastric lumen. This was because the layer would not leave the stomach until later, due to its buoyancy and the positions maintained by the volunteer inside and outside of the scanner to prevent any floating layers reaching the pylorus. Hence the oil fraction measurements could be combined with the aqueous-phase stomachemptying data to estimate the mean cumulative mass of oil leaving the stomach with time and hence the overall rates of energy delivery to the lower gastrointestinal tract for both meals. The overall rate of energy delivery from the stomach between meal ingestion and up to $t=110 \mathrm{~min}$ was estimated to be 8.3 (SE 0.9$) \mathrm{kJ} / \mathrm{min}$ for the acid-stable meal and 7 (SE 2) $\mathrm{kJ} / \mathrm{min}$ for the acid-unstable meal $(P<0 \cdot 8$; two-tailed paired Student's $t$ test). The error propagating on the estimation for the acid-unstable meal is higher than for the acid-stable meal due to the emptying rates and oil fraction being different for the two meals over time between $t=10 \mathrm{~min}$ and $t=110 \mathrm{~min}$.

\section{Plasma lipids and tracer in chylomicron lipid fraction}

The mean mass of lipid calculated from plasma TAG concentration is shown in Fig. 5 (a). The meal effect on the plasma TAG concentration was not significant $(P<0 \cdot 3$; two-way ANOVA) and no significant difference was found in the AUC (from 0 to $12 \mathrm{~h}$ ) for the mean mass of lipid (14 (SE 3) $\mathrm{g} \times \mathrm{h} / 1$ for the acid-stable $v .13(\mathrm{SE} 2) \mathrm{g} \times \mathrm{h} / \mathrm{l}$ for the acidunstable meal) $(P<0.7$; two-tailed paired Student's $t$ test). The mean mass concentration of labelled $\left[1,2,3,4-{ }^{13} \mathrm{C}\right]$ palmitic acid found in the chylomicron lipid fraction is shown in Fig. 5 (b). The mean mass concentration of $\left[{ }^{13} \mathrm{C}\right]$ palmitic acid tracer in the chylomicron lipid fraction was significantly higher following the acid-stable fat emulsion (two-way ANOVA for meal effect $P<0.04$, with a positive meal $\times$ time interaction, $P<0.05)$. A rise in plasma chylomicron levels of labelled lipid from 54 (SE 18) to 130 (SE 53) $\mu \mathrm{g} / \mathrm{ml}$ after the acid-unstable meal was observed from $4 \mathrm{~h}$ to $6 \mathrm{~h}$, suggesting a response to the second meal but this difference was not significant $(P<0.07$; two-tailed paired 


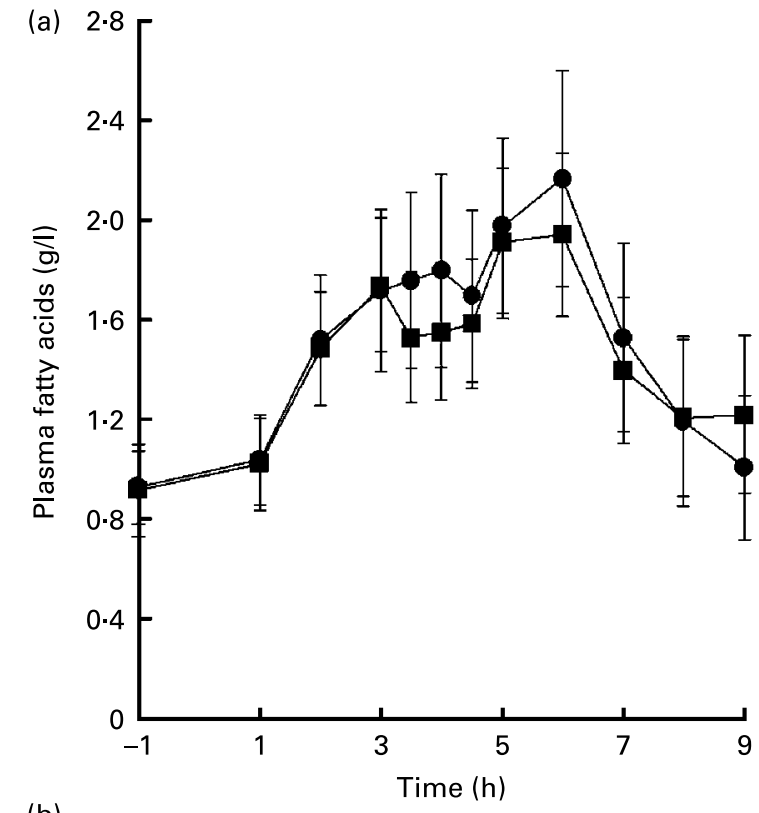

(b)

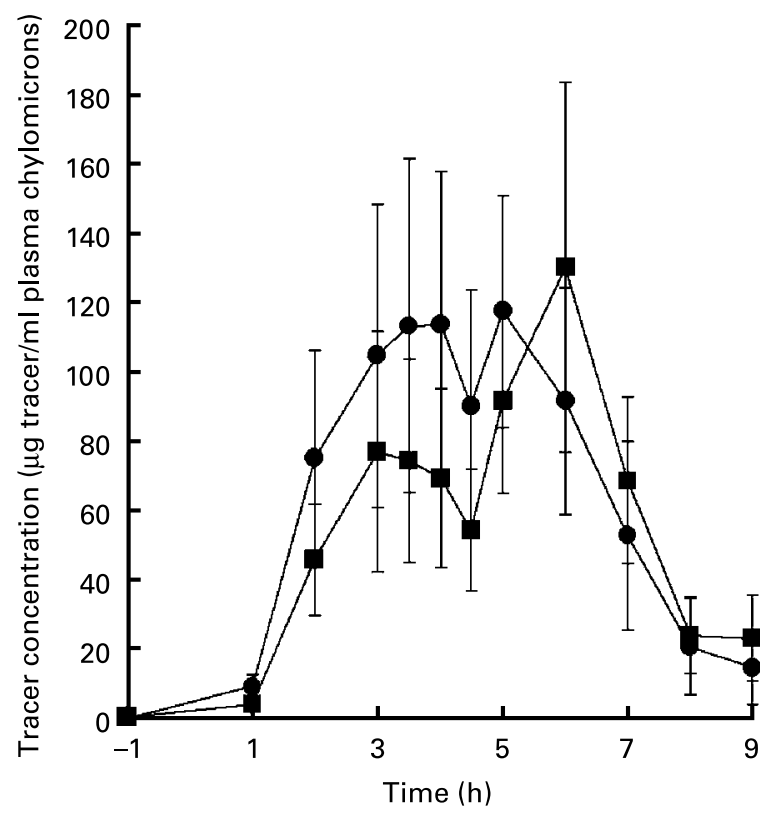

Fig. 5. Plots of the plasma lipid measurements for the acid-stable $(\bullet)$ and the acid-unstable (ם) emulsion meals. (a) Mass of lipid calculated from plasma TAG concentration; (b) mass concentration of ${ }^{13} \mathrm{C}$-enriched palmitic acid found in the chylomicron lipid fraction. Both are expressed in weight and having assumed a mean plasma volume of 3 litres. Values are means, with standard errors represented by vertical bars. The mean mass concentration of $\left[{ }^{13} \mathrm{C}\right]$ palmitic acid tracer in the chylomicron lipid fraction was significantly higher following the acid-stable fat emulsion (two-way ANOVA for meal effect $P<0.04$, with a positive meal $\times$ time interaction, $P<0.05$ ). For details of subjects and procedures, see the Materials and methods section.

Student's $t$ test). No similar rise was seen with the acid-stable meal (see Fig. 5 (b)).

\section{Discussion}

The present study has confirmed our previous results that have shown that it is possible to design oil-in-water emulsions with different intragastric behaviours to manipulate gastric emptying ${ }^{(40-42)}$. Within the present study it is clear that our acidstable emulsion maintains a constant oil volume fraction (Fig. 3) consistent with a homogenously dispersed emulsion. The oil volume fraction of the acid-unstable emulsion instead drops within the first data point, identifying that a significant proportion of the oil is contained within the floating phase identified in Fig. 1. The intragastric handling of the fat emulsions depends on whether or not they layer in the acid intragastric environment. If a fat emulsion meal is unstable in the gastric environment, so that the emulsion breaks, then if the subject is maintaining a normal vertical posture (or when the subject lies right side down in the magnet at intervals as in the present study) then most of the fat within the meal will tend to float to the upper surface of the gastric lumen, away from the pylorus. This means that the bulk (watery) phase of the meal will be emptied before any floating (fatty) layer. This means that the gastric volume after the unstable meal fell much more rapidly so that in the present study the stomach volume $1 \mathrm{~h}$ after the meal was nearly half of that found after the stable emulsion. Since gastric volume is an important determinant of desire to eat more, this would be expected to markedly alter subsequent food ingestion. Despite these big differences in gastric volume we found only modest changes in desire to eat. This may reflect the fact that energy delivery to the duodenum is the most important determinant of appetite and this did not differ substantially between the meals.

The present study found that the intragastric behaviour of fat emulsions influences the subsequent sensations of satiety. We found that the acid-stable emulsion meal made subjects feel fuller, less hungry and have less appetite compared with the acid-unstable emulsion meal. We found similar trends in our previous study ${ }^{(41)}$, although in that study most changes did not reach significance, possibly because fewer subjects were involved. One might speculate that the resulting decrease in the sense of satiety is due simply to the prolonged distension of the gastric wall which is detected by mechanoreceptors $^{(36,48-50)}$. However, this would not explain the 'second-meal effect' on satiety of the fat emulsion first meal observed here, the persistence of the decreased sense of satiety until after the second meal. Here we did not monitor the gastric emptying of the second meal, but there was no difference found in the emptying of a second meal after feeding these emulsion meals in a previous study ${ }^{(41)}$.

Nonetheless, despite the opposite intragastric behaviours of the two fat emulsion meals used in the present study we estimated that both emulsion meals delivered energy from the stomach to the duodenum between meal ingestion and $t=110 \mathrm{~min}$ at a consistent overall rate of approximately $8 \mathrm{~kJ} / \mathrm{min}$. This is within the expected range $(8-12 \mathrm{~kJ} / \mathrm{min}$ $(2-3 \mathrm{kcal} / \mathrm{min}))$ of energy emptied from the stomach found in healthy humans ${ }^{(51)}$. Thus the gastric emptying rate is modulated between the acid-stable and acid-unstable fat emulsion meals to provide a constant rate of energy delivery to the small intestine between the acid-stable and acid-unstable fat emulsion meals. Lipid-induced inhibition of gastric emptying is mediated in part by cholecystokinin- $\mathrm{A}$ receptors and a vagal sensory pathway ${ }^{(52)}$. For this reason the acid-stable meal, which contains more fat in the bulk phase of the meal, empties more slowly. Though we could estimate the energy 
delivery rate only up to $110 \mathrm{~min}$, this finding is in agreement with previous observations ${ }^{(28,29)}$ and would suggest that lipid as an accessible but integral part of a meal in a real dietary context could be more satiating.

Although it can be inferred that the gastric emptying rate varied three-fold to control the amount of oil arriving in the duodenum for both fat emulsions as estimated up to $t=110 \mathrm{~min}$, none the less the droplet size of the lipid emulsion reaching the duodenum between the two meals will have been markedly different. The acid-stable meal will have been delivered as a consistent fine emulsion. The acidunstable emulsion will have significantly broken within the acid environment and the droplet size distribution will have significantly increased with a proportion coalescing into a bulk oil phase which was observed to float on the surface of the gastric contents. One might hypothesise that the 'remains' of the acid-unstable emulsion would offer a smaller surface to gastric lipase and bile and pancreatic enzymes, reducing the rate of lipolysis in the proximal small intestine and producing fewer mixed micelles proximally causing absorption to be somewhat delayed and more spread along the small intestine. More lipid from the acid-unstable meal could be stored in the mucus layer or the enterocytes because of delayed lipolysis. This would be consistent with the decreased satiety arising from the acid-unstable meal and the trend for delay in lipid absorption seen in Fig. 5 (b) and by the second peak of plasma chylomicron ${ }^{13} \mathrm{C}$ tracer following the second meal $^{(53,54)}$. Plasma fatty acids were starting to fall when the second meal was provided. As is often the case with fatty meals a second meal stimulates a second plasma lipid peak. It is assumed that the second peak is derived from lipid temporarily stored in the enterocyte and is not concomitant with gastric emptying. Bi-model fat tolerance curves extending well beyond gastric emptying of the test meal are normal. This phenomenon is also sometimes seen (depending on the timing of samples) in the plasma concentration of hydrophobic nutrients that follow lipid absorption such as carotenoids.

This contrasts with the work of Armand et al. ${ }^{(19)}$ who found postprandial plasma TAG responses of similar amplitudes for two meals containing different droplet sizes but found that the kinetics of changes in postprandial plasma lipid were different, with a delayed appearance of the peak with the finer emulsion. However, in that study the fine emulsion had a median droplet size of $0.7 \mu \mathrm{m}$ (mean droplet diameter was not given) which is significantly below the size range of the emulsions used here and each meal $(500 \mathrm{ml})$ provided $3290 \mathrm{~kJ}(787 \mathrm{kcal}): 57 \%$ as fat $(50 \mathrm{~g}$ fat $)$, $26 \%$ as carbohydrate, and $17 \%$ as protein. This represents a higher total energy but a lower energy from fat than provided by the meal used in the present study.

The present study had some limitations. One was the artificiality of the two oil emulsion test meals which had low palatability, but which were chosen to represent extremes to investigate mechanisms. The surfactants used (polyoxyethylene sorbitan monostearate and sorbitan monooleate) are sorbitol-NEFA esters that are believed to be digested well and absorbed at the brush border through de-esterification. They are inactivated during the process of absorption and hence they should not influence the process of production and export of chylomicrons. Indeed, the ${ }^{13} \mathrm{C}$-label data indicated that the overall systemic delivery of fat over $12 \mathrm{~h}$ in the present study was similar, suggesting that significant fat malabsorption did not result from the changes in emulsifiers.

It was no longer possible to visualise the floating fat layer of the acid-unstable emulsion meal once the bulk aqueous phase had emptied. Therefore it was not possible to determine whether the fat layer emptied rapidly after the water phase or was retained in the gastric lumen for longer. The present study used EPI since that was the only imaging sequences available on the $0.5 \mathrm{~T}$ scanner at the time. However, more conventional fat-selective MRI imaging sequences or half-Fourier acquisition single-shot turbo spin-echo (HASTE) sequences could probably detect the fate of the fat layer. This is the focus of current work.

\section{Acknowledgements}

The present study was funded by the Biotechnology and Biological Sciences Research Council (BBSRC, Swindon, Wilts, UK; research grant D14043). None of the authors had any personal or financial conflict of interest. R. C. S., P. A. G., L. M., J. W. and A. F.-T. contributed to experimental design and project supervision. L. M. and E. F. C. contributed to MRI scanning, data analysis and writing of the manuscript. M. S. J. W. and R. F. contributed to test meal design and characterisation. R. F. contributed to plasma lipid and energy delivery analysis. D. B. and B. P. contributed to blood sampling and plasma collection. All authors contributed to editing the manuscript. The authors would like to thank Macphie (Glenbervie, Stonehaven, UK) for their kind gift of the Tween 60 emulsifier.

\section{References}

1. Mokdad AH, Ford ES, Bowman BA, Dietz WH, Vinicor F, Bales VS \& Marks JS (2003) Prevalence of obesity, diabetes, and obesity-related health risk factors, 2001. JAMA 289, 76-79.

2. Guinard JX, Zoumas-Morse C, Mori L, Uatoni B, Panyam D \& Kilara A (1997) Sugar and fat effects on sensory properties of ice cream. J Food Sci 62, 1087-1094.

3. Ghosh S, Peterson DG \& Coupland JN (2007) Aroma release from solid droplet emulsions: effect of lipid type. J Am Oil Chem Soc 84, 1001-1014.

4. Weel KGC, Boelrijk AEM, Burger JJ, Jacobs MA, Gruppen H, Voragen AGJ \& Smit G (2004) Effect of emulsion properties on release of esters under static headspace, in vivo, and artificial throat conditions in relation to sensory intensity. J Agric Food Chem 52, 6572-6577.

5. Little TJ, Russo A, Meyer JH, Horowitz M, Smyth DR, Bellon M, Wishart JM, Jones KL \& Feinle-Bisset C (2007) Free fatty acids have more potent effects on gastric emptying, gut hormones, and appetite than triacylglycerides. Gastroenterology 133, 1124-1131.

6. Pilichiewicz AN, Little TJ, Brennan IM, Meyer JH, Wishart JM, Otto B, Horowitz M \& Feinle-Bisset C (2006) Effects of load, and duration, of duodenal lipid on antropyloroduodenal motility, plasma CCK and PYY, and energy intake in healthy men. Am J Physiol 290, R668-R677.

7. Feltrin KL, Little TJ, Meyer JH, Horowitz M, Smout A, Wishart J, Pilichiewicz AN, Rades T, Chapman IM \& FeinleBisset C (2004) Effects of intraduodenal fatty acids on appetite, antropyloroduodenal motility, and plasma CCK and GLP-1 in 
humans vary with their chain length. Am $J$ Physiol 287, R524-R533.

8. Boulby P, Moore R, Gowland P \& Spiller RC (1999) Fat delays emptying but increases forward and backward antral flow as assessed by flow-sensitive magnetic resonance imaging. Neurogastroenterol Motil 11, 27-36.

9. Gautier JF, Chen KW, Salbe AD, Bandy D, Pratley RE, Heiman M, Ravussin E, Reiman EM \& Tataranni PA (2000) Differential brain responses to satiation in obese and lean men. Diabetes $\mathbf{4 9}$, 838-846.

10. Read N, French S \& Cunningham K (1994) The role of the gut in regulating food intake in man. Nutr Rev 52, 1-10.

11. Batterham RL, Cowley MA, Small CJ, et al. (2002) Gut hormone PYY3-36 physiologically inhibits food intake. Nature 418, 650-654.

12. Armand M, Hamosh M, Mehta NR, Angelus PA, Philpott JR, Henderson TR, Dwyer NK, Lairon D \& Hamosh P (1996) Effect of human milk or formula on gastric function and fat digestion in the premature infant. Pediatr Res 40, 429-437.

13. Fredrikzon B \& Blackberg L (1980) Lingual lipase: an important lipase in the digestion of dietary lipids in cystic fibrosis. Pediatr Res 14, 1387-1390.

14. Fink CS, Hamosh P \& Hamosh M (1984) Fat digestion in the stomach: stability of lingual lipase in the gastric environment. Pediatr Res 18, 248-254.

15. Abrams CK, Hamosh M, Lee TC, Ansher AF, Collen MJ, Lewis JH, Benjamin SB \& Hamosh P (1988) Gastric lipase: localization in the human stomach. Gastroenterology 95, $1460-1464$.

16. Moreau H, Laugier R, Gargouri Y, Ferrato F \& Verger R (1988) Human preduodenal lipase is entirely of gastric fundic origin. Gastroenterology 95, 1221-1226.

17. Hamosh M, Klaeveman HL, Wolf RO \& Scow RO (1975) Pharyngeal lipase and digestion of dietary triglyceride in man. $J$ Clin Invest 55, 908-913.

18. Armand M, Borel P, Dubois C, Senft M, Peyrot J, Salducci J, Lafont H \& Lairon D (1994) Characterization of emulsions and lipolysis of dietary lipids in the human stomach. Am J Physiol 266, G372-G381.

19. Armand M, Pasquier B, Andre M, Borel P, Senft M, Peyrot J, Salducci J, Portugal H, Jaussan V \& Lairon D (1999) Digestion and absorption of two fat emulsions with different droplet sizes in the human digestive tract. Am J Clin Nutr 70, 1096-1106.

20. Carriere F, Renou C, Ransac S, et al. (2001) Inhibition of gastrointestinal lipolysis by Orlistat during digestion of test meals in healthy volunteers. Am J Physiol 281, G16-G28.

21. O'Donovan D, Horowitz M, Russo A, Feinle-Bisset C, Murolo N, Gentilcore D, Wishart JM, Morris HA \& Jones KL (2004) Effects of lipase inhibition on gastric emptying of, and on the glycaemic, insulin and cardiovascular responses to, a high-fat/carbohydrate meal in type 2 diabetes. Diabetologia 47, 2208-2214.

22. Malmud LS, Fisher RS, Knight LC \& Rock E (1982) Scintigraphic evaluation of gastric emptying. Semin Nucl Med 12, $116-125$.

23. Meyer JH, MacGregor IL, Gueller R, Martin P \& Cavalieri R (1976) Tc-99-m-tagged chicken liver as a marker of solid food in the human stomach. Dig Dis Sci 21, 296-304.

24. Christian PE, Moore JG \& Datz FL (1984) Comparison of Tc-99m labeled liver and liver pate as markers for solid phase gastric emptying. J Nucl Med 25, 364-366.

25. Collins PJ, Horowitz M \& Chatterton BE (1988) Proximal, distal and total stomach emptying of a digestible solid meal in normal subjects. Br J Radiol 61, 12-18.

26. Kerlin P, Byrnes O \& Wong L (1989) Radiolabeled unprocessed bran - validation of a practical labeling technique and evaluation of gastrointestinal transit profiles in health. $J$ Gastroenterol Hepatol 4, 119-126.

27. Heading RC, Tothill P, Laidlow AJ \& Shearman DJC (1971) An evaluation of 113-In-DTPA chelate in the measurement of gastric emptying by scintiscanning. Gut 12, 611-615.

28. Cunningham KM, Baker RJ, Horowitz $M$, Maddox AF, Edelbroek MAL \& Chatterton BE (1991) Use of technetium$99 \mathrm{~m}(\mathrm{~V})$ thiocyanate to measure gastric emptying of fat. $\mathrm{J} \mathrm{Nucl}$ Med 32, 878-881.

29. Jian R, Vigneron N, Najean Y \& Bernier JJ (1982) Gastric emptying and intragastric distribution of lipids in man - a new scintigraphic method of study. Dig Dis Sci 27, $705-711$

30. Horowitz M, Collins PJ \& Shearman DJC (1985) Disorders of gastric emptying in humans and the use of radionuclide techniques. Arch Intern Med 145, 1467-1472.

31. Edelbroek M, Horowitz M, Maddox A \& Bellen J (1992) Gastric emptying and intragastric distribution of oil in the presence of a liquid or a solid meal. J Nucl Med 33, 1283-1290.

32. Mansfield P \& Maudsley AA (1977) Planar spin imaging by NMR. J Magn Reson 27, 101-119.

33. Evans DF, Lamont G, Stehling MK, Blamire AM, Gibbs P, Coxon R, Hardcastle JD \& Mansfield P (1993) Prolonged monitoring of the upper gastrointestinal tract using echo-planar magnetic resonance imaging. Gut 34, 848-852.

34. Schwizer W, Maecke H \& Fried M (1992) Measurement of gastric emptying by magnetic resonance imaging in humans. Gastroenterology 103, 369-376.

35. Stehling MK, Evans DF, Lamont G, Ordidge RJ, Howseman AM, Chapman B, Coxon R, Mansfield P, Hardcastle JD \& Coupland RE (1989) Gastrointestinal tract - dynamic MR studies with echo-planar imaging. Radiology 171, 41-46.

36. Marciani L, Gowland PA, Spiller RC, Manoj P, Moore RJ, Young P \& Fillery-Travis AJ (2001) Effect of meal viscosity and nutrients on satiety, intragastric dilution, and emptying assessed by MRI. Am J Physiol 280, G1227-G1233.

37. Schwizer W, Fraser R, Borovicka J, Crelier G, Boesiger P \& Fried M (1994) Measurement of gastric emptying and gastric motility by magnetic resonance imaging (MRI). Dig Dis Sci 39, S101-S103.

38. Boulby P, Gowland P, Adams V \& Spiller RC (1997) Use of echo planar imaging to demonstrate the effect of posture on the intragastric distribution and emptying of an oil/water meal. Neurogastroenterol Motil 9, 41-47.

39. Kunz P, Feinle-Bisset C, Faas H, Boesiger P, Fried M, Steingotter A \& Schwizer W (2005) Effect of ingestion order of the fat component of a solid meal on intragastric fat distribution and gastric emptying assessed by MRI. J Magn Reson Imaging 21, $383-390$

40. Marciani L, Wickham M, Hills BP, Wright J, Bush D, Faulks R, Fillery-Travis A, Spiller RC \& Gowland PA (2004) Intragastric oil-in-water emulsion fat fraction measured using inversion recovery echo-planar magnetic resonance imaging. J Food Sci 69, E290-E296.

41. Marciani L, Wickham M, Singh G, Bush D, Pick B, Cox E, Fillery-Travis A, Faulks R, Marsden C, Gowland PA \& Spiller RC (2007) Enhancement of intragastric acid stability of a fat emulsion meal delays gastric emptying, increases cholecystokinin release and gallbladder contraction. Am J Physiol 292, G1607-G1613.

42. Marciani L, Wickham M, Bush D, Faulks R, Wright J, FilleryTravis A, Spiller RC \& Gowland PA (2006) Magnetic resonance imaging of the behaviour of oil-in-water emulsions in the gastric lumen of man. Br J Nutr 95, 331-339.

43. Hill AJ, Rogers PJ \& Blundell JE (1995) Techniques for the experimental measurement of human eating behavior and food intake - a practical guide. Int J Obes 19, 361-375. 
44. Stubbs RJ, Hughes DA, Johnstone AM, Rowley E, Reid C, Elia M, Stratton R, Delargy H, King N \& Blundell JE (2000) The use of visual analogue scales to assess motivation to eat in human subjects: a review of their reliability and validity with an evaluation of new hand-held computerized systems for temporal tracking of appetite ratings. Br J Nutr 84, 405-415.

45. Borel P, Tyssandier V, Mekki N, Grolier P, Rochette Y, Alexandre-Gouabau MC, Lairon D \& Azais-Braesco V (1998) Chylomicron $\beta$-carotene and retinyl palmitate responses are dramatically diminished when men ingest $\beta$-carotene with medium-chain rather than long-chain triglycerides. $J$ Nutr 128, 1361-1367.

46. Howseman AM, Stehling MK, Chapman B, Coxon R, Turner R, Ordidge RJ, Cawley MG, Glover P, Mansfield P \& Coupland RE (1988) Improvements in snap-shot nuclear magnetic resonance imaging. $\mathrm{Br} J$ Radiol 61, 822-828.

47. Lentner C (editor) (1985) Geigy Scientific Tables: Physical Chemistry Composition of Blood Hematology Somatometric Data. Basel, Switzerland: Icon Learning Systems.

48. French SJ \& Read NW (1994) Effect of guar gum on hunger and satiety after meals of differing fat content - relationship with gastric emptying. Am J Clin Nutr 59, 87-91.
49. Khan MI, Read NW \& Grundy D (1993) Effect of varying the rate and pattern of gastric distension on its sensory perception and motor-activity. Am J Physiol 264, G824-G827.

50. Tack J, Piessevaux H, Coulie B, Caenepeel P \& Janssens J (1998) Role of impaired gastric accommodation to a meal in functional dyspepsia. Gastroenterology 115, 1346-1352.

51. Horowitz M, Edelbroek MAL, Wishart JM \& Straathof JW (1993) Relationship between oral glucose tolerance and gastric emptying in normal healthy subjects. Diabetologia 36, 857-862.

52. Berthoud HR \& Patterson LM (1996) Anatomical relationship between vagal afferent fibers and CCK-immunoreactive entero-endocrine cells in the rat small intestinal mucosa. Acta Anat 156, 123-131.

53. Evans K, Kuusela PJ, Cruz ML, Wilhelmova I, Fielding BA \& Frayn KN (1998) Rapid chylomicron appearance following sequential meals: effects of second meal composition. $\mathrm{Br} J$ Nutr 79, 425-429.

54. Fielding BA, Callow J, Owen RM, Samra JS, Matthews DR \& Frayn KN (1996) Postprandial lipemia: the origin of an early peak studied by specific dietary fatty acid intake during sequential meals. Am J Clin Nutr 63, 36-41. 